\title{
US-alone presentations as an extinction procedure*
}

\author{
JOHN J. B. AYRES and JAMES O. BENEDICT \\ University of Massachusetts, Amherst, Massachusetts 01002
}

\begin{abstract}
CS-alone trials or US-alone trials were interpolated between Pavlovian defense conditioning and later measurement of the Paviovian CR (conditionco suppression of dipper licking). Although both procedures equally degraded the CS-US contingency, only the CS-alone procedure significantly weakened the previously established CR. The US-alone procedure appeared to have no effect.
\end{abstract}

In Pavlovian forward conditioning, the US is more likely to occur if the CS has just occurred than if it hasn't. The CS is said to predict the US, and the US is said to be contingent on the CS. According to a recent view (Rescorla, 1967), this contingency is responsible for excitatory conditioning and its elimination is responsible for extinction (p. 75).

The usual method of producing extinction following a series of CS-US pairings is to present a series of CSs alone. Comparison of Fig. 1A and Fig. 1B shows that this procedure does indeed degrade the CS-US contingency as required by the contingency view. Presenting CSs alone, however, is not the only method of degrading a contingency. Comparison of Fig. $1 \mathrm{~A}$ and Fig. 1C shows that presenting a series of USs alone following a series of CS-US pairings also degrades the CS-US contingency. According to the contingency view, this method should also produce extinction.

The prediction that US-alone presentations should produce extinction of a Pavlovian CR is counterintuitive and has not been confirmed by previous work (e.g., Kimble, Mann, \& Dufort, 1955; Pavlov, 1960, p. 139). However, these studies were not designed within the context of the contingency view, so no attempt was made to degrade the contingency to any particular value with the US presentations and no comparable CS-alone procedure was run for purposes of comparison. The purpose of the present study was to provide such a comparison. Three groups of rats were given CS-shock pairings. One group then received a series of CSs alone; a second received a series of USs alone; and a third, serving as a control, received only exposure to the apparatus. All three groups were then presented with the CS while licking sucrose. The degree of suppression in lick rate was taken as an index of the strength of the Pavlovian $\mathrm{CR}$ remaining after the various extinction procedures.

*Supported in part by grants to John J. B. Ayres from the Research Council of the University of Massachusetts and by Grant MH-18661-01 from the National Institute of Mental Health. We wish to thank M. J. DeCosta, P. Konowitch, and S. P. Nault for their assistance in collecting the data. We also thank $J$. W. Donahoe for his critical review of an earlier version of the manuscript. The present results were presented at the 1970 meeting of the Psychonomic Society in San Antonio.

\section{METHOD}

\section{Subjects}

The Ss were 36 male albino rats. 90 days old upon arrival from Gofmoor Farms, Westboro, Massachusetts. They were housed individually and fed ad lib for 7 days. Then, over a 5 -day period, they were fed $3-5 \mathrm{~g}$ daily, reducing them to $80 \%$ of their free-feeding weights, at which they were maintained throughout the study. W'ater was always available in their home cages.

\section{Apparatus}

Six Gerbrands operant conditioning chambers with left-side dipper feeders were housed in ventilated $.61-\mathrm{m}$ cubes of $13-\mathrm{mm}$ plywood lined with acoustical tile. A .61-m-square sheet of Masonite covered the tile floor of each cube. Dipper licking (the response to be suppressed) was monitored by Grason-Stadler drinkometers and cumulated on printout counters. Sucrose of $8 \%$ concentration made daily with tap water and presented in I-cc dipper cups was used to maintain responding. The CS was the onset of a $1,000-\mathrm{Hz} 84-\mathrm{dB}$ tone and the simultaneous off set of an $87-\mathrm{dB}$ white noise normally on for background masking. Scrambled grid shocks of 1.6-mA intensity from six Grason-Stadler shock sources served as USs. The chambers were illuminated by a $28-\mathrm{V}$ cue lamp centered over the dipper hole and mounted $95 \mathrm{~mm}$ above the floor.

\section{Procedure}

\section{Preliminary Training}

On the sixth day of restricted feeding, Ss were taught to lick

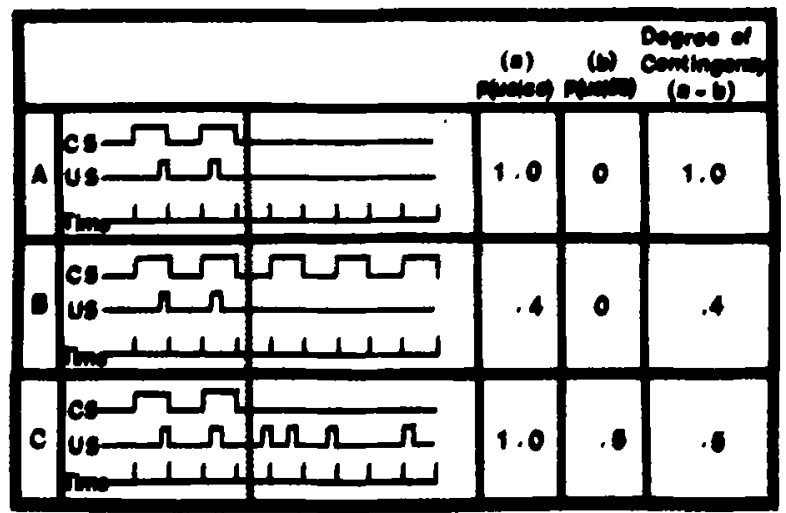

Fig. 1. Schematic showing how a series of CSs or USs given after CS-US pairings can reduce the CS-US contingency. 1 


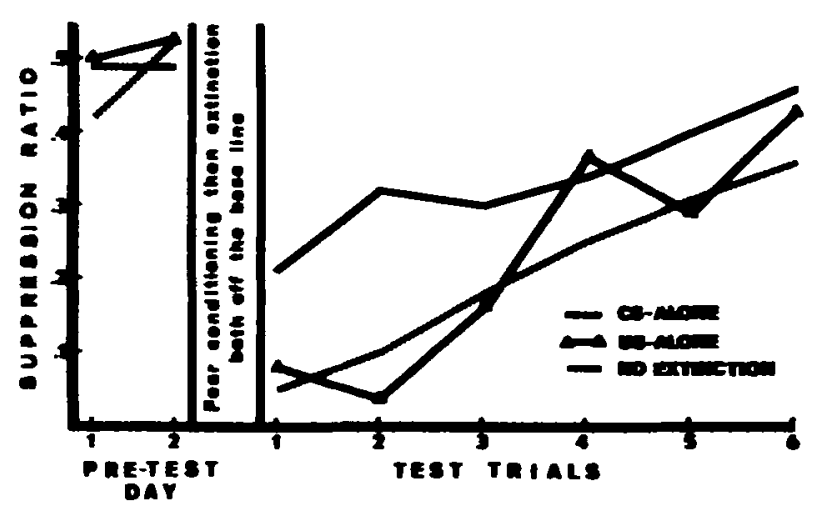

Fig. 2. Effects of CS-alone and US-alone presentations interpolated between defense conditioning and later measurement of conditioned suppression.

sucrose from the dippers. Then, beginning the following day, all Ss were exposed to nine consecutive sessions given at about the same time daily. The first two were pretest sessions designed to measure the unconditioned effects of the CS on licking. In these sessions, while the dippers were repeatedly raised for $3 \mathrm{sec}$ (making sucrose available) and then lowered for $2 \mathrm{sec}$ throughout a $15-\mathrm{min}$ period, $1-\mathrm{min}$ CSs occurred in Minute 6 and in Minute 10 .

\section{Conditioning}

On each of the next 2 days, each group received 10 pairings of a 20-sec CS followed after a 45-50-msec delay by a $2-\sec 1.6-\mathrm{mA}$ shock. Inter-CS intervals were identical for all Ss and ranged from 19 to $208 \mathrm{sec}$ on the furst conditioning day and from 24 to $242 \mathrm{sec}$ on the second. Pairings were given "off the baseline." i.e., while Ss were prevented from licking (by a Masonite insert). The duration of both conditioning sessions was $15 \mathrm{~min}$.

\section{Extinction}

On the following day, the different extinction treatments were given while $S$ s were again prevented from licking. The CS-alone group received 17 presentations of the $20-\mathrm{sec}$ CS distributed randomly throughout the 20 -min session. The LS-alone group received 60 presentations of the US alone. One US appeared at a time. selected randomly and independently for each 20 -sec interval of the session. The no-extinction group received only the same exposure to the conditioning apparatus that the other groups received. That the CS-alone and US-alone procedures actually degraded the contingency equally was shown as follows: Over the combined conditioning and extinction sessions, the CS-alone group received $20 \mathrm{CS}$-US pairings and 17 CSs alone. Therefore, at the end of extinction, the P(US ICS) was .54. Since no USs ever appeared alone, the P(US I $\overline{C S})$ was zero. The degree of contingency at the end of extinction was $\mathrm{P}(\mathrm{US} \mid \mathrm{CS})-\mathrm{P}(\mathrm{US} \mid \overline{\mathrm{CS}})$ or $\mathbf{5 4}$. The US-alone group received 20 CS-US pairings. In addition, 60 of the 130 non CS intervals in acquisition and extinction contained USs. (A non-CS interval is a period of time equal in duration to the CS but not containing a CS.) Thus, at the end of extinction, the P(US ICS) was 1.00 and the P(US $\mid \overline{C S})$ was .46 . The degree of contingency was therefore .54. (Assumptions underlying these calculations and those of Fig. 1 are discussed in Note 1.)

\section{Rate Recovery}

In the next session, Ss were allowed to recover their baseline lick rates so that meaningful suppression measures could be obtained in later sessions. Each $\mathrm{S}$ was allowed 200 licks, then was removed from the box.

\section{Test for Conditioning}

The final three sessions were test sessions just like the pretest sessions and were used to measure the effectiveness of the off-the-baseline extinction procedures on conditioned suppression of licking. To minimize the contribution of fear of static apparatus cues to the measures of CS-elicited suppression, the apparatus cues in the test sessions were made discriminably different from those in the shock sessions in the following manner: On all but the conditioning and extinction days, an aluminum sheet, held down by spring clips, covered the grid floor. But on the conditioning and extinction days, the aluminum floor was removed and a four-walled Masonite insert with $19-\mathrm{mm}$ vertical black and white stripes was placed inside the conditioning chamber. Also, the voltage across the cue lamp, which provided the only illumination in the chamber, was increased from the normal 6 to $26 \mathrm{~V}$; white paper was placed in the bottom of the litter tray to increase reflectance onto the striped inserts.

\section{TREATMENT OF DATA}

Conditioned suppression was indexed by a suppression ratio defined as $D /(B+D)$. D represents the number of responses occurring during the $1-\mathrm{min} \mathrm{CS}$, and $B$ represents the number in the $1 \mathrm{~min}$ before the $\mathrm{CS}$. The ratio varies from 0 (maximum suppression) through .5 (no effect) to 1.0 (facilitation). If $\mathrm{Ss}$ failed to respond before or during a CS, they were given the suppression ratio they obtained on the other trial on that day. If they failed to respond on both trials, they were given their group mean for those trials. In both cases, df were reduced in statistical analyses. Six of 216 scores were estimated in this way ( 2 scores from each group).

\section{RESULTS $^{2}$}

CS-elicited suppression before and after experimental treatment is shown in Fig. 2. The figure suggests that the CS had no pretreatment effect on any of the groups but produced strong suppression in all groups after treatment. More importantly, the figure suggests that the treatment weakened conditioning more for the CS-alone group than for the other two groups.

Planned statistical comparisons involving two-tailed $t$ tests substantiated these impressions. There were no reliable differences between groups prior to treatment, but on the first day after treatment (Test Trials 1 and 2), the CS-alone group suppressed significantly less than either the US-alone or no-extinction groups (ps $<.005$ ).

To determine whether the differences in the suppression ratios in Fig. 2 were due to differences in pre-CS response rates, possibly caused by the experimental treatment and not eliminated by the rate-recovery session, both the absolute pre-CS and CS response rates were carefully examined. Table 1 shows that the pre-CS rate of the no-extinction group was slightly higher than that of the remaining groups on all the days of the experiment. The table also shows that the pre-CS rates of all three groups did not recover completely after the rate-recovery session and that the 
experimental extinction treatments tended to enhance the difference between the no-extinction group and the remaining groups. Differences between groups were not reliable, however, on either pretest day or on Test Day 1. The difference between the no-extinction and US-alone groups did attain significance on Test Day 2 $(p<.05)$. Note that Groups CS-alone and US-alone, which suppressed differentially to the CS (see Fig. 2), had essentially identical pre-CS rates throughout the experiment.

Table 1 also suggests that the three groups had similar rates during the CS prior to experimental treatment but that the CS-alone group responded faster than the other two groups during the CS after treatment. On Test Day 1, in particular, the CS rate of the CS-alone group was more than twice that of the remaining groups and the difference between Groups CS-alone and US-alone was highly reliable $(p=.02)$. The difference between Group CS-alone and and Group No-extinction was reliable only with a one-tailed test $(\mathrm{p}=.038)$.

Taken as a whole, the analysis of the CS and pre-CS response rates suggests that the between-group differences in the suppression ratios shown in Fig. 2 were due to differences in response rates during the CS and were not artifacts of differences in pre-CS rates. This conclusion is supported by a correlational analysis that showed a correlation of 0.00 between pre-CS response rates and the suppression ratios coupled with a correlation of +0.95 between $C S$ rates and suppression ratios (Pearson product-moment correlation based on data from Test Trials 1-4).

\section{DISCUSSION}

Of two different methods of degrading the CS-US contingency, only one, the CS-alone procedure, appeared to weaken conditioning. The other, the US-alone procedure, appeared to have no effect. It is possible that the US-alone procedure really did weaken conditioning but simultaneously induced a motivational change that carried over into the test sessions and offset the weakening of conditioning. Such a motivational change, however, would presumably be reflected in the Ss' pre-CS response rates, and, as shown in Table 1, the pre-CS rates of the CS-alone and US-alone groups were essentially identical.

Since only one method of degrading the contingency appeared to produce extinction, the possibility is suggested that degrading a contingency is not the critical variable in producing extinction of a Pavlovian fear $C R$. In contrast to the contingency view, an older theory of Solomon and Wynne (1954) holds that extinction of a fear CR occurs to the extent that it is fully elicited in the absence of contiguous USs. This condition is, of course, met by the CS-alone procedure but not by the US-alone procedure. The present findings are consistent with this older view.

The present findings are also consistent with a recent
Table 1

Mean Pre-CS and CS Response Rates (Licks Per Minute)

\begin{tabular}{lcccccr}
\hline & \multicolumn{2}{c}{ Pretest Session } & \multicolumn{3}{c}{ Test Session } \\
\cline { 2 - 3 } \cline { 5 - 7 } Group & Day 1 & Day 2 & Day 1 & Day 2 & Day 3 \\
CS Alone & 131 & 129 & 89 & 131 & 136 \\
US Alone & 112 & 131 & 91 & 128 & 137 \\
No Extinction & 137 & 141 & 123 & 150 & 156 \\
& & & CS Rate & & \\
CS Alone & 124 & 128 & 44 & 77 & 112 \\
US Alone & 118 & 145 & 9 & 63 & 83 \\
No Extinction & 121 & 148 & 17 & 53 & 88 \\
\hline
\end{tabular}

mathematical model of conditioning described by Rescorla and Wagner (1970). In contrast to the contingency view, this model does not regard US-alone presentations as acting retroactively to degrade previously established CS-US informational or predictive relationships; instead, it views US-alone presentations as acting proactively to block or attenuate conditioning that would otherwise result from succeeding pairings. Since there were no succeeding pairings in the present experiment, the model predicts correctly that only the CS-alone presentations should have weakened the previously established CR.

\section{REFERENCES}

Ayres, J. J. B., \& DeCosta, M. J. The truly random control as an extinction procedure. Psychonomic Science, 1971, 24, 31-33.

Kimble, G. A., Mann, L. I., \& Dufort, R. H. Classical and instrumental eyelid conditioning. Journal of Experimental Psychology, 1955, 49, 407-417.

Pavlov, I. P. Conditioned reflexes. New York: Dover, 1960.

Rescorla, R. A. Pavlovian conditioning and its proper control procedures. Psychological Review, 1967, 74, 71-80.

Rescorla, R. A. Probability of shock in the presence and absence of $\mathrm{CS}$ in fear conditioning. Journal of Comparative \& Physiological Psychology, 1968, 66, 1-5.

Rescorla, R. A., \& Wagner, A. R. A theory of Pavlovian conditioning: Variations in the effectiveness of reinforcement and nonreinforcement. In A. Black and W. F. Prokasy (Eds.), Classical conditioning. New York: Appleton-Century-Crofts, 1970.

Solomon, R. L., \& Wynne, L. C. Traumatic avoidance learning: The principles of anxiety conservation and partial irreversibility. Psychological Review, 1954, 61, 353-385.

\section{NOTES}

1. In Fig. 1, the contingency is perfect in Panel $A$ and to the left of the dotted line in Panels $B$ and $C$, but has been reduced by events occurring to the right of the dotted line in Panels $\mathrm{B}$ and $C$. The $P(U S \mid C S)$ has been computed by dividing the number of pairings by the total number of CSs. The P(US $\mid \overline{C S}$ ) has been computed by dividing the number of USs alone by the total number of non-CS intervals. A non-CS interval is defined as a period of time equal in duration to the CS but not containing a CS. This method of computing the conditional probabilities is based on a description of an experimental procedure used by Rescorla (1968). However, Rescorla has not stated how the conditional probabilities are to be combined into the singlc predictive statistic that contingency theory must provide if it is 
to predict the outcomes of different extinction procedures and extinction procedures of different durations. The simplest combination rule consistent with the contingency view might be the subtraction rule shown in the right column of the figure. When $\mathrm{P}(\mathrm{L}$ S $\mid C S)$ - $\mathrm{P}(\mathrm{L}$ 'S $\mid \overline{\mathrm{CS}})$ is positive, a positive contingency exists: when it is negative. a negative contingency exists; and, when the two probabilities are equal, no contingency exists. Nevertheless. since contingency theory has yet to specify a combination rule. one may choose to interpret the present experiment and that of Ayres and DeCosta (1971) as tests of the subtraction rule rather than as tests of contingency theory per se.

2. Data from two $S s$ in each group were lost on the final day of the experiment due to an apparatus failure. Therefore. the means for this session (Test Day 3) plotted in Fig. 2 and in Table 1 are based on only $10 \mathrm{Ss}$ per group. Data from this session were not included in the statistical analysis.

(Received for publication July 10, 1972; revision received September 15,1972 ) 